\title{
Induction of prolonged survival of CD4+ T lymphocytes by intermittent IL-2 therapy in HIV-infected patients
} William Sachau, ${ }^{4}$ Grace Kelly, ${ }^{1}$ Julia A. Metcalf, ${ }^{4}$ Richard T. Davey Jr., ${ }^{4}$ Judith Falloon, ${ }^{4}$ Michael A. Polis, ${ }^{4}$ Jorge Tavel, ${ }^{4}$ Randy Stevens, ${ }^{2}$ Laurie Lambert, ${ }^{2}$ Douglas A. Hosack, ${ }^{2}$ Marjorie Bosche, ${ }^{2}$ Haleem J. Issaq, ${ }^{2}$ Stephen D. Fox, ${ }^{2}$ Susan Leitman, ${ }^{5}$ Michael W. Baseler, ${ }^{2}$ Henry Masur, ${ }^{1}$ Michele Di Mascio, ${ }^{6}$ Dimiter S. Dimitrov, ${ }^{3}$ and H. Clifford Lane ${ }^{4}$

${ }^{1}$ Critical Care Medicine Department, Warren G. Magnuson Clinical Center, NIH, Bethesda, Maryland, USA. ${ }^{2}$ Science Applications International Corp., Frederick, Maryland, USA. ${ }^{3}$ Laboratory of Experimental and Computational Biology, Center for Cancer Research, National Cancer Institute-Frederick, Frederick, Maryland, USA. ${ }^{4}$ Laboratory of Immunoregulation, National Institute of Allergy and Infectious Diseases, ${ }^{5}$ Department of Transfusion Medicine, Warren G. Magnuson Clinical Center, and ${ }^{6}$ Biostatistics Research Branch, Office of Clinical Research, National Institute of Allergy and Infectious Diseases, NIH, Bethesda, Maryland, USA.

HIV infection leads to decreases in the number of $\mathrm{CD} 4^{+} \mathrm{T}$ lymphocytes and an increased risk for opportunistic infections and neoplasms. The administration of intermittent cycles of IL-2 to HIV-infected patients can lead to profound increases (often greater than $100 \%$ ) in CD4 cell number and percentage. Using in vivo labeling with ${ }^{2} \mathrm{H}$-glucose and BrdU, we have been able to demonstrate that, although therapy with IL-2 leads to high levels of proliferation of CD4 as well as CD8 lymphocytes, it is a remarkable preferential increase in survival of CD4 cells (with half-lives that can exceed 3 years) that is critical to the sustained expansion of these cells. This increased survival was time-dependent: the median half-life, as determined by semiempirical modeling, of labeled CD4 cells in 6 patients increased from 1.7 weeks following an early IL-2 cycle to 28.7 weeks following a later cycle, while CD8 cells showed no change in the median half-life. Examination of lymphocyte subsets demonstrated that phenotypically naive $\left(\mathrm{CD}^{2} 7^{+} \mathrm{CD} 45 \mathrm{RO}^{-}\right)$as well as central memory $\left(\mathrm{CD}^{2} 7^{+} \mathrm{CD} 45 \mathrm{RO}^{+}\right) \mathrm{CD}^{4}$ cells were preferentially expanded, suggesting that IL-2 can help maintain cells important for host defense against new antigens as well as for long-term memory to opportunistic pathogens.

\section{Introduction}

Multiple randomized trials have demonstrated that the administration of intermittent cycles of IL-2 to HIV-infected patients can lead to profound, sustained increases (often greater than 100\%) in CD4 cell number and percentage (1-3). After 3 to 6 five-day cycles of IL-2 administered every 2 months, CD 4 cell numbers may remain elevated for years without additional cycles. While this therapy causes marked changes in CD4 numbers, only minimal changes are seen in CD8 or NK cell numbers (1). The CD4 increases are preferentially in cells of a naive phenotype (4-6).

The mechanisms leading to these increases have remained obscure. Ex vivo studies have documented increases in proliferation and death of CD8 as well as CD4 cells during an IL-2 cycle, suggesting that while increased proliferation may play a role, proliferation alone does not explain the preferential expansion of CD4 relative to CD8 cells $(4,7)$. Quantitation of $\mathrm{T}$ cell receptor excision circles and examination of thymic scans before and after administration of IL-2 suggest that thymic output does not play a major role $(7,8)$.

Recently, techniques to study cell turnover in vivo using deuterium or BrdU to label proliferating cells have been developed and

Nonstandard abbreviations used: $m / z$, mass-to-charge ratio.

Conflict of interest: The US government has been granted a use patent for intermittent IL-2 therapy, including H.C. Lane and J.A. Kovacs as inventors.

Citation for this article: J. Clin. Invest. 115:2139-2148 (2005).

doi:10.1172/JCI23196. used to examine lymphocyte turnover in HIV-infected patients before and after highly active antiretroviral therapy (9-11). In the current study, we used these methods to demonstrate a profound effect of intermittent IL-2 therapy on lymphocyte turnover that is characterized by an increase in proliferation during therapy, followed by a remarkable increase in survival, primarily of $\mathrm{CD} 4$ cells, after completion of therapy.

\section{Results}

Intermittent IL-2 therapy can substantially and preferentially increase $\mathrm{CD} 4$ cell numbers for prolonged periods, maintaining CD4 counts above baseline for over 10 years in some instances (Figure 1). In order to examine the effects of IL-2 on lymphocyte proliferation, a 5 -day infusion of ${ }^{2} \mathrm{H}$-glucose was administered to 8 healthy controls, 9 patients with HIV infection, and 18 patients with HIV infection receiving IL-2, and enrichment of ${ }^{2} \mathrm{H}$-deoxyadenosine in the genomic DNA of CD4 and CD8 cells was determined. Patient characteristics are shown in Table 1. IL-2 therapy was associated with a marked increase in ${ }^{2} \mathrm{H}$-deoxyadenosine incorporation and thus in proliferation of both CD4 and CD8 cells (Figure 2A). Peak $\mathrm{CD}^{+} \mathrm{T}$ cell labeling increased approximately 7 - to 18 -fold during IL-2 administration (44\% [range, $25-81 \%] ; n=18$ ) compared with that in HIV-infected volunteers not receiving IL-2 (6\% [range, $4-11 \%] ; n=9 ; P<0.001)$ or HIV- volunteers $(2.5 \%$ [range, $0.9-5 \%$ ]; $n=8 ; P<0.001)$. Similarly, peak CD8 labeling was approximately 6 - to 12 -fold higher for the IL-2 group (29\% [range, $13-58 \%$ ] vs. $5 \%$ [range, $2-12 \%$ ] and vs. $2.6 \%$ [range, $0.9-9 \%$ ]; $P<0.001$ for both com- 

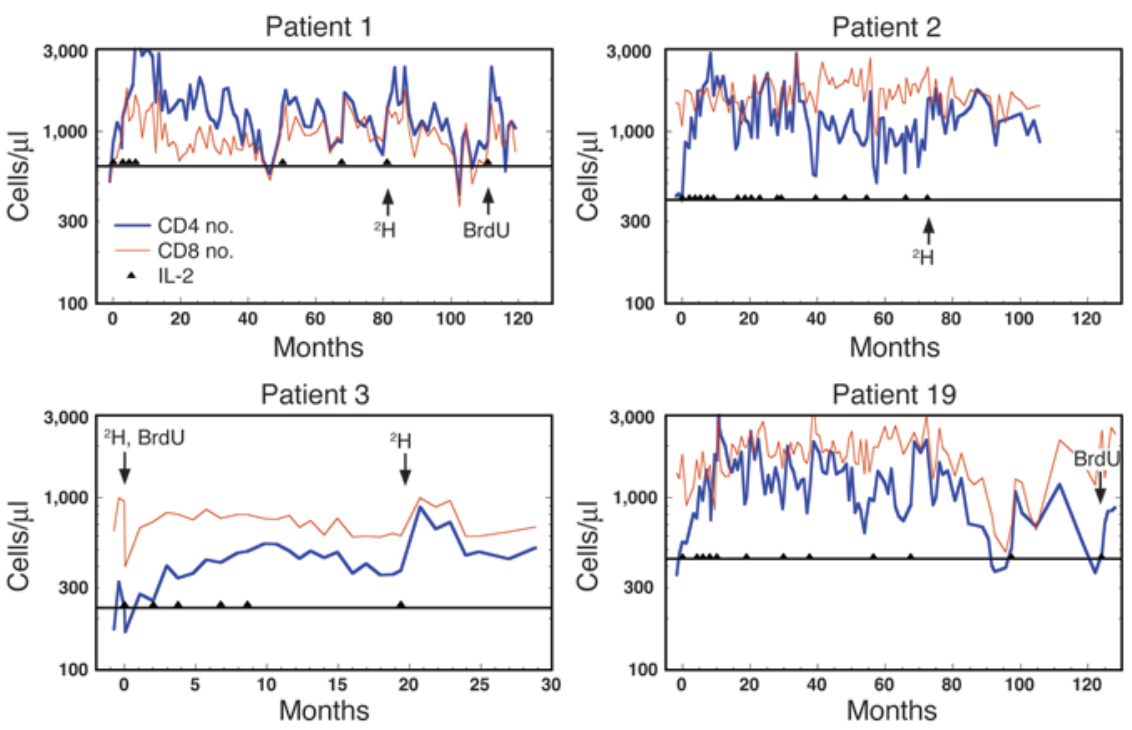

Figure 1

CD4 and CD8 counts over time for 4 responders to intermittent IL-2 therapy who also participated in labeling studies. The blue lines indicate CD4 cell counts and the red lines indicate CD8 cell counts. The black lines indicate the baseline CD4 counts (mean of 3 values) immediately before the start of IL-2 therapy. Triangles represent individual 5-day IL-2 cycles (3 million to 18 million IU/d). Arrows indicate the IL-2 cycle during which labeling with ${ }^{2} \mathrm{H}$-glucose $\left({ }^{2} \mathrm{H}\right)$ or $\mathrm{BrdU}$ was performed. parisons). CD4 labeling was consistently and significantly higher $(P<0.004)$ than CD8 labeling in patients receiving IL-2. This difference between CD4 and CD8 labeling was less pronounced and not significant in the control groups $\left(P=0.07\right.$ for $\mathrm{HIV}^{+} ; P=0.5$ for $\left.\mathrm{HIV}^{-}\right)$. Thus, IL-2 substantially increases in vivo production of both CD4 and CD8 cells, with greater increases for CD4 cells.

To examine the long-term effects of IL- 2 on lymphocyte survival, 2 long-term (6-7 years) responders to IL-2 therapy received a 5-day infusion of ${ }^{2} \mathrm{H}$-glucose with their 7 th and 17 th IL-2 cycles, respectively (Figure 1, patients 1 and 2). Both showed high peak labeling of CD 4 and CD 8 cells: $64 \%$ and $56 \%$ for CD 4 cells, and $56 \%$ and $27 \%$ for CD8 cells (Figure 2C, patients 1 and 2). Decay of ${ }^{2} \mathrm{H}$-adenosine-labeled DNA, monitored over a 2- to 3-year period, was surprisingly slow for CD4 cells. The calculated half-lives of CD 4 cells for these 2 patients, based solely on the decay slopes (using a log scale), were 3.4 years and 3.2 years, respectively. Similar calculations for the half-life for healthy controls (e.g., Figure 2B, patient 30) and for HIV-infected patients not receiving IL-2 (e.g., Figure 2B, patients 20 and 22) were 8 weeks (median; range, 3-20 weeks) and 7 weeks (range, $3-14$ weeks). While a more rapid loss of label was seen in CD8 cells compared with CD4 cells, the half-lives of CD 8 cells in the 2 patients receiving IL- 2 were also prolonged at 1.2 and 0.9 years, respectively, versus 7 weeks (range, 4-9 weeks) and 7 weeks (range, 4-13 weeks) for controls. In both patients the labeling of lymph node CD4 and CD8 cells obtained 3 months after labeling was similar to that of peripheral blood cells (Figure $2 \mathrm{C}$, patients 1 and 2 ) and considerably higher than that previously reported in $\mathrm{HIV}^{+}$patients not receiving IL-2 (9).

Given these results, we extended the studies to include a patient who had not shown an increase in CD4 cell numbers with IL-2 (Figure 2C, patient 4) and 9 patients who had recently begun IL-2 therapy. In the patient who did not show an increase in CD4 cell numbers in response to IL-2 despite 22 cycles (but elected to continue IL-2 therapy to potentially maintain a stable CD4 count), peak labeling of CD 4 cells was similar to that in other IL-2 recipients at $38 \%$, but decay of label was more rapid, with a half-life of 11 weeks.

More rapid decay kinetics responses were also seen in the 9 patients during an early (first or second) IL-2 cycle compared with those studied during a later cycle. These results suggest that repeat cycles of IL-2 are necessary to prolong survival of CD4 cells. To examine this directly, 6 patients who had deuterium labeling during an early cycle received a second deuterium infusion (and 1 patient received a third infusion) with a later IL-2 cycle (Figure 3). While peak labeling was similar for the 2 cycles, in 5 of 6 patients, the decay of label of CD4 cells was slower with the later cycle; there was no difference between cycles 1 and 3 in patient 10 (Figure $3 \mathrm{~A}$ ). In contrast, $\mathrm{CD} 8$ cells did not appear to show a change in the decay of label as a function of cycle number (Figure 3C).

Given that linear regression provided a poor fit to the data, a semiempirical model based on a modification of an earlier model (11) was developed to describe the labeled cell decay kinetics. This current model is based on the concept that a distribution of different decay rate constants exists that can be described by a limited number of parameters. We tested several standard distributions and found that the distribution that best fit the experimental data was a log-normal distribution characterized by 3 parameters: $m_{d}$, mean $\log$ decay rate constant $(\log d) ; \sigma_{d}$, standard deviation of $\log d$; and $S$, total source, which correlates with the number of proliferating cells. Figure $2 \mathrm{C}$ illustrates the fitting of the data to the model, and Figure $2 \mathrm{D}$ the probability density function of the normal distribution of $\log d$ for the same patients. In the latter, the location on the $x$ axis of the peak of the curve represents the average (log-transformed) decay constant for the entire population of labeled cells, the splay of the curve (which is a function of the standard deviation) represents the homogeneity of the population with regard to decay constants (less homogeneous populations have a wider splay), and the area under the curve (which is a function of $S$ ) correlates with the number of proliferating cells. A shift to the left of the peak of the curve represents a slower decay.

In comparing these parameters for $\mathrm{HIV}^{-}$versus $\mathrm{HIV}^{+}$patients not receiving IL-2, we found a significant difference in $S$ for both CD4 $(P=0.04)$ and CD8 $(P=0.02)$ cells, and a difference in $m_{d}$ for CD4 cells only $(P=0.03$; Table 2$)$. Significant differences were seen in $S$ for both CD4 $(P<0.001)$ and CD8 cells $(P<0.001)$ and in $m_{d}$ for CD4 $(P<0.001)$, but not CD8, cells when HIV-infected patients receiving IL-2 (at least 3 cycles) were compared with those not receiving IL-2 (Table 2). Thus, more CD4 and CD8 cells proliferated during IL-2 therapy, and, for the group as a whole, the CD4, 
but not the CD8, cells that proliferated survived longer in patients receiving multiple cycles of IL-2 therapy compared with controls.

When early (second or earlier) and late (third or later) IL-2 cycles were compared, proliferation was similar, but CD4 cells showed a significantly slower decay $(P=0.04)$ after late IL-2 cycles whereas CD8 cells showed no difference (Table 2). Similar results for $m_{d}$ were seen when the 6 patients who received deuterium infusions during an early as well as a later IL- 2 cycle were examined $(P=0.01$ for CD 4 cells, and $P=0.41$ for CD8 cells; Table 2 and Figure 3, A-D). This slower decay led to a longer half-life for the CD4 cell pool following later cycles of IL-2: the median half-life of labeled CD4 cells (calculated from the mean decay rate constants) for the 15 patients with labeling during cycles 3-28 (Table 2) was approximately 37.6 weeks, while the comparable half-life for CD8 cells was 7.9 weeks.

In vivo BrdU labeling confirmed the ${ }^{2} \mathrm{H}$-glucose labeling studies. BrdU labeling was used in 4 patients receiving IL-2 to allow

Table 1

Patient characteristics at the time of labeling

\begin{tabular}{|c|c|c|c|c|c|c|c|c|c|}
\hline Patient no. & Age & Sex & $\begin{array}{l}\text { CD4 no. } \\
\text { (cells/ul) }\end{array}$ & CD4 \% & $\begin{array}{l}\text { CD8 no. } \\
\text { (cells/ul) }\end{array}$ & CD8 \% & $\begin{array}{l}\text { Plasma HIV load } \\
\text { (copies/ml) }\end{array}$ & $\begin{array}{c}\text { IL-2 } \\
\text { cycle no.A }\end{array}$ & Labeling agent \\
\hline \multicolumn{10}{|c|}{ IL-2 recipients } \\
\hline \multirow[t]{2}{*}{1} & 36 & $M$ & 1,347 & 46 & 1,377 & 47 & $<50$ & 7 & ${ }^{2} \mathrm{H}$-glucose \\
\hline & & & 861 & 46 & 786 & 42 & 3,877 & 8 & BrdU \\
\hline 2 & 33 & $M$ & 1,532 & 31 & 2,372 & 48 & 374 & 17 & ${ }^{2} \mathrm{H}$-glucose \\
\hline \multirow[t]{2}{*}{3} & 41 & $M$ & 228 & 13 & 948 & 54 & $<50$ & 1 & ${ }^{2} \mathrm{H}$-glucose, BrdU \\
\hline & & & 357 & 26 & 618 & 45 & $<50$ & 6 & ${ }^{2} \mathrm{H}$-glucose \\
\hline 4 & 46 & $M$ & 147 & 9 & 1,173 & 72 & 32,873 & 22 & ${ }^{2} \mathrm{H}$-glucose \\
\hline \multirow[t]{3}{*}{5} & 53 & $M$ & 391 & 15 & 1,487 & 57 & 54 & 1 & ${ }^{2} \mathrm{H}$-glucose \\
\hline & & & 551 & 23 & 1,246 & 52 & 59 & 3 & ${ }^{2} \mathrm{H}$-glucose \\
\hline & & & 609 & 20 & 1,584 & 52 & 2,307 & 4 & ${ }^{2} \mathrm{H}$-glucose \\
\hline \multirow[t]{2}{*}{6} & 44 & $M$ & 527 & 28 & 997 & 53 & $<50$ & 2 & ${ }^{2} \mathrm{H}$-glucose \\
\hline & & & 537 & 31 & 936 & 54 & $<50$ & 4 & 2H-glucose \\
\hline \multirow[t]{2}{*}{7} & 49 & $M$ & 723 & 26 & 1,446 & 52 & 2,597 & 2 & ${ }^{2} \mathrm{H}$-glucose \\
\hline & & & 581 & 31 & 974 & 52 & 2,900 & 5 & ${ }^{2} \mathrm{H}$-glucose \\
\hline \multirow[t]{2}{*}{8} & 47 & $\mathrm{M}$ & 861 & 33 & 1,487 & 57 & $<50$ & 3 & ${ }^{2} \mathrm{H}$-glucose, BrdU \\
\hline & & & 674 & 33 & 1,082 & 53 & $<50$ & 4 & $2 \mathrm{H}$-glucose \\
\hline 9 & 51 & M & 343 & 14 & 1,766 & 72 & 4,862 & 1 & ${ }^{2} \mathrm{H}$-glucose \\
\hline \multirow[t]{2}{*}{10} & 49 & $\mathrm{M}$ & 444 & 22 & 1,251 & 62 & $<50$ & 1 & ${ }^{2} \mathrm{H}$-glucose \\
\hline & & & 498 & 22 & 1,427 & 63 & $<50$ & 3 & $2 \mathrm{H}$-glucose \\
\hline 11 & 46 & $M$ & 779 & 26 & 1,288 & 43 & $<50$ & 2 & ${ }^{2} \mathrm{H}$-glucose \\
\hline 12 & 41 & $M$ & 335 & 34 & 473 & 48 & $<50$ & 9 & ${ }^{2} \mathrm{H}$-glucose \\
\hline 13 & 53 & $M$ & 923 & 36 & 1,154 & 45 & $<50$ & 26 & ${ }^{2} \mathrm{H}$-glucose \\
\hline 14 & 52 & $\mathrm{M}$ & 710 & 28 & 1,090 & 43 & 2,352 & 28 & ${ }^{2 H}$-glucose \\
\hline 15 & 44 & $\mathrm{M}$ & 1,049 & 49 & 663 & 31 & $<50$ & 10 & ${ }^{2} \mathrm{H}$-glucose \\
\hline 16 & 45 & $M$ & 947 & 37 & 973 & 38 & 3,064 & 10 & ${ }^{2} \mathrm{H}$-glucose \\
\hline 17 & 42 & $M$ & 485 & 35 & 471 & 34 & 61 & 1 & $2 \mathrm{H}$-glucose \\
\hline 18 & 54 & $M$ & 748 & 41 & 675 & 37 & $<50$ & 14 & ${ }^{2} \mathrm{H}$-glucose \\
\hline 19 & 53 & $M$ & 473 & 15 & 2,459 & 78 & $<50$ & 12 & BrdU \\
\hline \multicolumn{10}{|c|}{$\mathrm{HIV}^{+}$, no IL-2 } \\
\hline 3 & 41 & $M$ & 280 & 16 & 981 & 56 & 105 & & ${ }^{2} \mathrm{H}$-glucose \\
\hline 20 & 41 & $M$ & 423 & 16 & 1,561 & 59 & 74 & & ${ }^{2} \mathrm{H}$-glucose \\
\hline 21 & 40 & $M$ & 422 & 32 & 607 & 46 & 487 & & ${ }^{2} \mathrm{H}$-glucose \\
\hline 22 & 36 & $M$ & 263 & 18 & 965 & 66 & 1,792 & & ${ }^{2} \mathrm{H}$-glucose \\
\hline 23 & 37 & $M$ & 582 & 26 & 1,074 & 48 & $<50$ & & ${ }^{2} \mathrm{H}$-glucose \\
\hline 24 & 34 & $M$ & 378 & 38 & 348 & 35 & $<50$ & & ${ }^{2} \mathrm{H}$-glucose \\
\hline 25 & 39 & $\mathrm{M}$ & 327 & 12 & 1,498 & 55 & 67 & & ${ }^{2} \mathrm{H}$-glucose \\
\hline 26 & 48 & $M$ & 443 & 30 & 754 & 51 & 19,187 & & ${ }^{2 H}$-glucose \\
\hline 27 & 42 & $\mathrm{~F}$ & 298 & 24 & 719 & 58 & 67 & & ${ }^{2} \mathrm{H}$-glucose \\
\hline \multicolumn{10}{|l|}{ HIV $^{-}$} \\
\hline 28 & 36 & $\mathrm{~F}$ & 1,655 & 63 & 236 & 9 & & & ${ }^{2} \mathrm{H}$-glucose \\
\hline 29 & 42 & $\mathrm{~F}$ & 1,187 & 40 & 1,187 & 40 & & & ${ }^{2 H}$-glucose \\
\hline 30 & 29 & $\mathrm{~F}$ & 885 & 45 & 531 & 27 & & & ${ }^{2} \mathrm{H}$-glucose \\
\hline 31 & 36 & $M$ & 1,012 & 48 & 696 & 33 & & & ${ }^{2} \mathrm{H}$-glucose \\
\hline 32 & 42 & $M$ & 1,574 & 54 & 904 & 31 & & & $2 \mathrm{H}$-glucose \\
\hline 33 & 37 & $\mathrm{~F}$ & 789 & 41 & 616 & 32 & & & ${ }^{2} \mathrm{H}$-glucose \\
\hline 34 & 40 & $\mathrm{~F}$ & 1,304 & 53 & 590 & 24 & & & ${ }^{2} \mathrm{H}$-glucose \\
\hline 35 & 48 & $\mathrm{~F}$ & 829 & 44 & 434 & 23 & & & ${ }^{2} \mathrm{H}$-glucose \\
\hline
\end{tabular}

AIL-2 cycle during which ${ }^{2} \mathrm{H}$-glucose or BrdU was administered. 

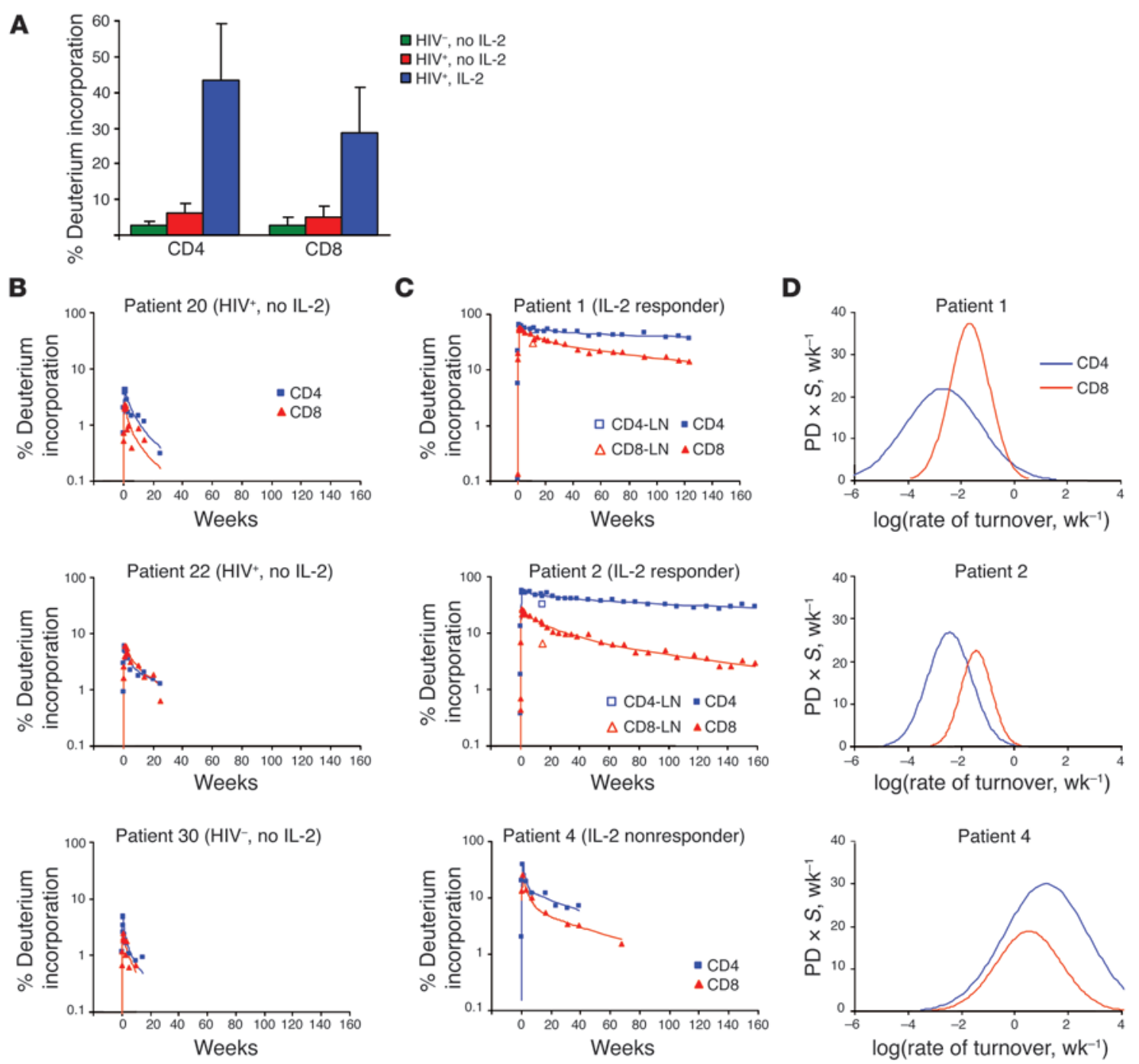

\section{Figure 2}

Deuterium incorporation by CD4 and CD8 cells. (A) Mean peak deuterium incorporation was significantly higher in HIV-infected patients receiving IL-2 $(n=18)$ for both CD4 and CD8 cell populations when compared with HIV-uninfected controls $(n=8)$ and HIV-infected patients who did not receive IL-2 $(n=9)(P<0.001$ for all comparisons, Student's $t$ test). Error bars represent the standard deviation. (B and C) Deuterium labeling kinetics in 2 HIV-infected patients who did not receive IL-2 (patients 20 and 22, Table 1) and an HIV- volunteer (patient 30 ) (B) and in 3 HIV-infected patients who were long-term participants in intermittent IL-2 studies (patients 1, 2, and 4) (C). Patients 1 and 2 were long-term responders (see Figure 1 and Table 1), while patient 4 did not exhibit a CD4 count increase during IL-2 therapy. The continuous lines represent the fitting of the experimental data points (individual symbols) by the model equations. For the first 2 patients, the open symbol represents the percentage deuterium incorporation in cells obtained from a lymph node biopsy (at approximately 3 months). Time 0 is the beginning of the ${ }^{2} \mathrm{H}$-glucose infusion, which started 2 days after initiation of IL-2 treatment. (D) The probability density function (PD) of the normal distribution of log $d$ multiplied by the total source of labeled cells $(S)$ for the patients in $\mathbf{C}$. The mean log decay rate constants $\left(m_{d}\right)$ for CD4/CD8 cells for the patients are, respectively: patient (pt.) 1, -2.68/-1.68; pt. 2, -2.44/-1.44; pt. 4, 1.16/0.52. One log difference represents a 10-fold difference in half-life.

better phenotypic characterization of proliferating cells (11). Since BrdU is administered by a 30-minute infusion and has a plasma half-life of less than 10 minutes (J.A. Kovacs, unpublished observations), it allows one to perform the equivalent of a pulse-chase experiment. Mean peak labeling of $24 \%$ and $18 \%$ was seen for CD4 and CD8 cells, respectively, after a 30-minute pulse. As in the ${ }^{2} \mathrm{H}$-glucose studies, these values are 5-to 10 -fold higher than those seen in studies of HIV-infected patients not receiving IL-2 (11). In addition, the 2 patients receiving BrdU during an earlier cycle of IL-2 (first and third cycles) showed a more rapid decay of label in CD4 cells than the 2 patients receiving BrdU during a later cycle (Figure 4, A and B). Again, CD8 cells did not show a similar trend.

Multiparameter flow cytometry in combination with in vivo BrdU labeling allowed for a more detailed analysis of the proliferating cells during IL-2 therapy. In 2 long-term responders (patients 1 and 19), both naive and memory CD 4 cells (defined by CD45RO alone) proliferated to similar levels in response to IL-2; however, the label in memory cells decayed more rapidly, suggesting that a primary mechanism leading to the preferential expansion of naive cells is preferential survival (data not shown). When CD27 expression was used to subdivide the memory cells into central memory 


\section{CD4 lymphocytes}

A

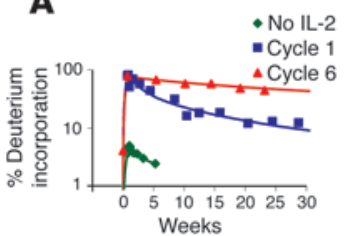

B
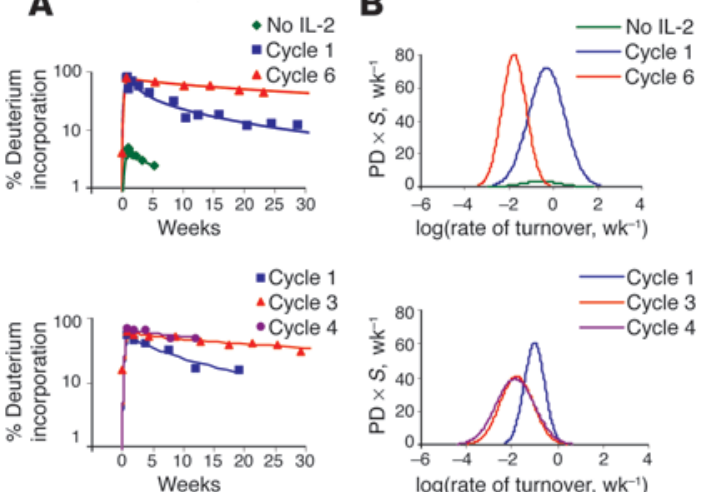

Weeks

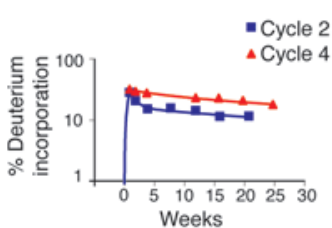

Weeks

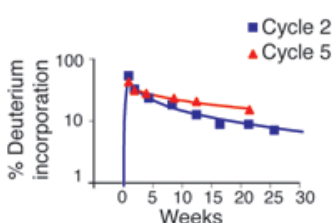

- Cycle 2
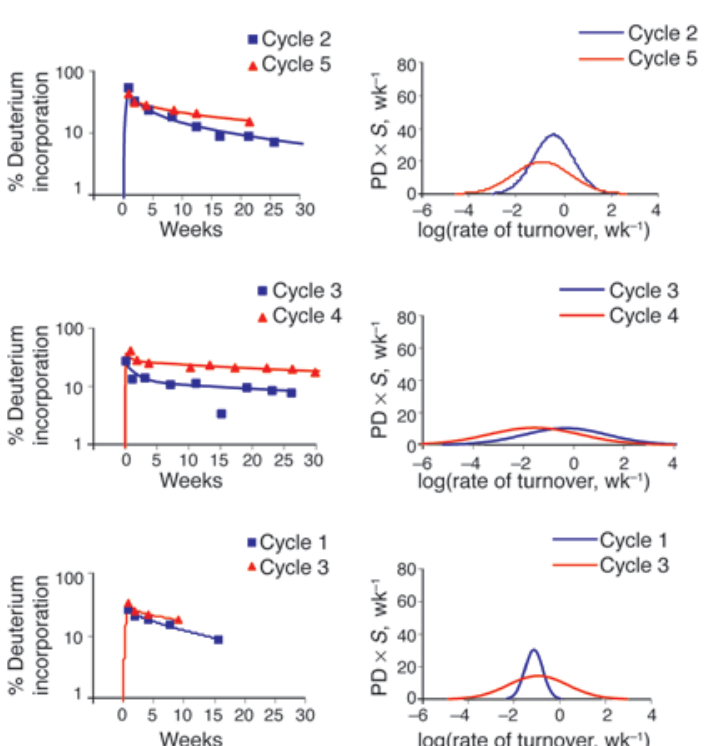
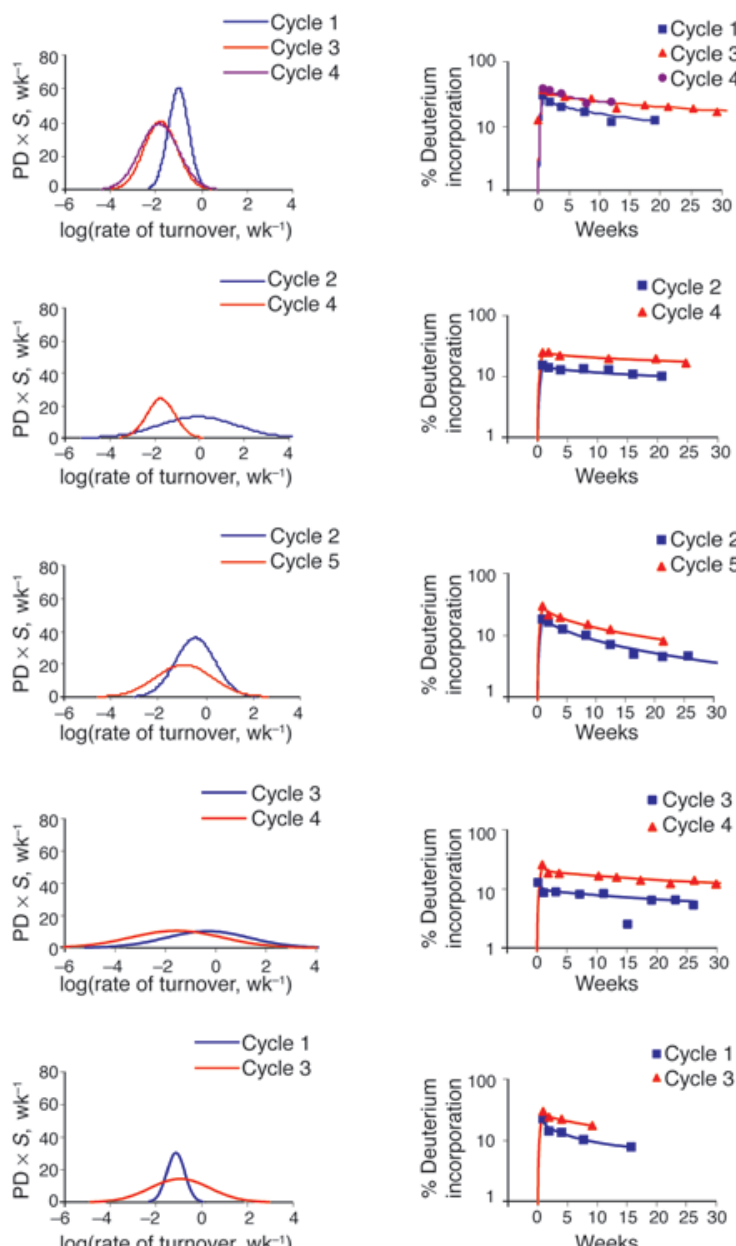

Cycle 2
C
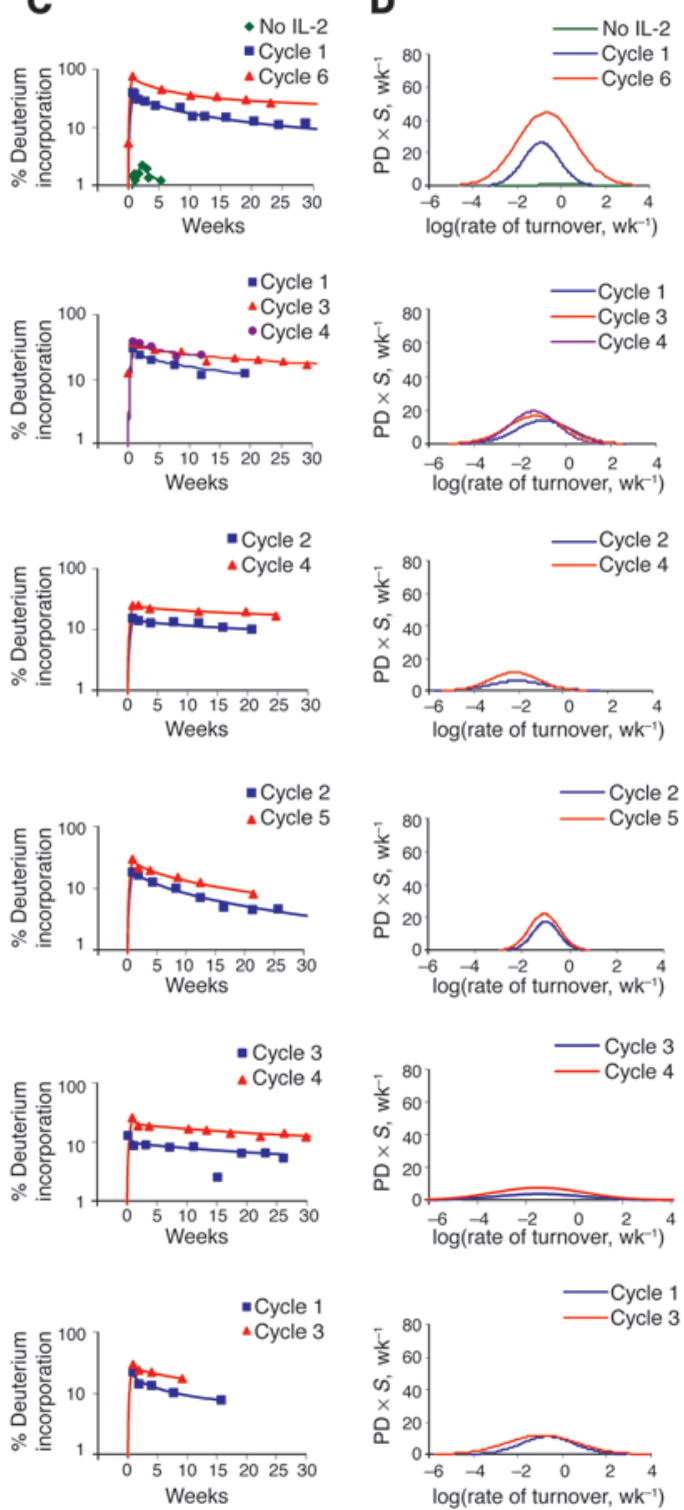

Patient 6

Patient 5

Patient 7

Patient 8

Patient 3

Patient 10

\section{Figure 3}

Slower decay of deuterium labeling in CD4 but not CD8 cells after later cycles of IL-2. (A and C) Mean log decay shifted to the left for CD4 cells (A) but not CD8 cells (C) in 5 of 6 patients, indicating a longer average survival of CD4 cells (but not CD8 cells) following later IL-2 cycles (3 to 6) compared to earlier cycles ( 1 to 3 ). Patient 3 had an infusion of ${ }^{2} \mathrm{H}$-glucose before beginning IL-2 therapy (green diamonds), and patient 5 received a third infusion during his fourth IL-2 cycle (purple circles). The solid lines represent the fitting by the model equations. (B and $\mathbf{D})$ The probability density function of the normal distribution of log $d$ multiplied by the total source of labeled cells $(S)$. Mean log decay rate constants for CD4/CD8 cells for the patients are, respectively: pt. $3,-0.59 / 0.06$ (no IL-2), $-0.33 /-0.91$ (cycle 1), $-1.79 /-0.68$ (cycle 6); pt. 5, $-1.03 /-0.95$ (cycle 1), $-1.80 /-1.30$ (cycle 3), -1.86/-1.39 (cycle 4); pt. 6, -0.09/-2.05 (cycle 2), -1.73/-2.19 (cycle 4); pt. 7, $-0.45 /-1.01$ (cycle 2), $-0.94 /-1.07$ (cycle 5); pt. 8, $-1.07 /-2.18$ (cycle 3), $-2.30 /-2.20$ (cycle 4); pt. 10, $-1.14 /-0.95$ (cycle 1), $-0.66 /-0.92$ (cycle 3 ).

$\left(\mathrm{CD} 27^{+} \mathrm{CD} 45 \mathrm{RO}^{+}\right)$and effector memory pools $\left(\mathrm{CD} 27^{-} \mathrm{CD} 45 \mathrm{RO}^{+}\right.$ and $\left.\mathrm{CD}^{2} 7^{-} \mathrm{CD} 45 \mathrm{RO}^{-}\right)(12)$, the mean log decay of the central memory pool $(-1.10)$ was similar to that of naive cells $(-1.58)$ (Figure 4C). Effector memory cells exhibited a more rapid decay (mean log decay, 0.69 and 2.32 , respectively).

Given these labeling results, we sought to determine whether long-term increases in the central memory pools occurred during intermittent IL-2 therapy. The percentage and number of naive, central memory, and effector memory cells were determined for 21 patients participating in a randomized trial of intermittent IL-2 therapy (13). Consistent with the labeling studies, a significantly greater increase in central memory CD4 cells was seen at 6 months $(P<0.001$; Table 3$)$ and 12 months $(P=0.006)$ in patients receiving IL-2 than in controls.

The prolonged survival of CD4 cells observed in this study could result either from an increase in the proportion of cells within a 


\section{Table 2}

Comparison of kinetic parameters for the different patient populations following deuterium labeling of proliferating cells

\begin{tabular}{|c|c|c|c|c|c|c|c|c|}
\hline \multirow[b]{2}{*}{ Cohort } & \multicolumn{4}{|c|}{ CD4 cells } & \multicolumn{4}{|c|}{ CD8 cells } \\
\hline & $n$ & $m_{d^{A}}{ }^{\mathrm{A}}$ & $\begin{array}{c}S^{A} \\
\left(w^{-1}\right)\end{array}$ & $\begin{array}{l}t_{1 / 2}{ }^{\mathrm{B}} \\
(\mathrm{wk})\end{array}$ & $n$ & $m_{d^{\mathrm{A}}}$ & $\begin{array}{c}S^{A} \\
\left(w^{-1}\right)\end{array}$ & $\begin{array}{l}t_{1 / 2^{\mathrm{B}}} \\
\text { (wk) }\end{array}$ \\
\hline Non-HIV & 8 & -0.67 & 3.4 & 4.1 & 7 & -0.09 & 2.1 & 0.8 \\
\hline HIV, no IL-2 & 9 & -0.02 & 15.1 & 0.5 & 9 & -0.58 & 6.5 & 2.1 \\
\hline IL-2, cycles 3-28 & 15 & -1.44 & 60.4 & 37.6 & 15 & -0.78 & 53.4 & 7.9 \\
\hline$P$, non-HIV vs. HIV, no IL-2 & & 0.03 & 0.04 & 0.03 & & 0.13 & 0.02 & 0.12 \\
\hline$P$, HIV, IL-2 vs. HIV, no IL-2 & & $<0.001$ & $<0.001$ & 0.001 & & 0.42 & $<0.001$ & 0.27 \\
\hline Patients with labeling during a s & & & & & & & & \\
\hline IL-2, cycles 1-2 & 3 & -0.48 & 107.4 & 1.9 & 3 & -0.47 & 89.8 & 2.3 \\
\hline IL-2, cycles 3-28 & 9 & -1.57 & 59.7 & 67.3 & 9 & -0.47 & 52.6 & 0.8 \\
\hline$P$, IL-2, early vs. late cycles & & 0.04 & 0.47 & 0.10 & & 0.99 & 0.56 & 0.93 \\
\hline Patients with labeling during 2 & & & & & & & & \\
\hline 1st labeling (IL-2, cycles $1-3$ ) & 6 & -0.54 & 69.7 & 1.7 & 6 & -1.15 & 31.3 & 6.6 \\
\hline 2nd labeling (IL-2, cycles 3-6) & 6 & -1.45 & 62.5 & 28.7 & 6 & -1.25 & 57.6 & 11.0 \\
\hline$P, \mathrm{IL}-2,1$ st vs. 2nd labeling & & 0.01 & 0.50 & 0.046 & & 0.41 & 0.11 & 0.46 \\
\hline
\end{tabular}

${ }^{A} m_{d}$, mean $\log _{10}\left(d, w^{-1}\right) ; S$, total source; mean values are shown; significance levels were calculated using Student's $t$ test. ${ }^{B} t_{1 / 2}=\ln 2 / 10^{m}{ }_{d}$; median values are shown; significance levels were calculated using nonparametric rank sum or signed-rank test.

subset that has a longer survival (e.g., naive cells) with no change in the decay kinetics of that subset, or, alternatively, from an increase in survival (slower decay) of cells within a given subset, or a combination of the two. As noted above and in Table 3, IL-2 does lead to an increase in the proportion of longer-lived naive cells. To determine whether there was also a change in decay kinetics, CD4 and CD8 cells obtained from patients 3, 5, and 6 after both early and late IL- 2 cycles were separately sorted into naive $\left(\mathrm{CD} 27^{+} \mathrm{CD} 45 \mathrm{RO}^{-}\right)$, central memory $\left(\mathrm{CD} 27^{+} \mathrm{CD} 45 \mathrm{RO}^{+}\right)$, and effector memory cells $\left(\mathrm{CD} 27^{-} \mathrm{CD} 45 \mathrm{RO}^{+}\right.$for $\mathrm{CD} 4$ cells, and CD27-CD45RO ${ }^{+}$and $\mathrm{CD}^{-} 7^{-}$ $\mathrm{CD}^{4} 5 \mathrm{RO}^{-}$for $\mathrm{CD} 8$ cells), and deuterium incorporation was determined for each subset. A similar analysis was performed for patients 1 and 2 following labeling after the single late IL-2 cycle. As illustrated in Figure 5, for patients 3, 5, and 6 there was a significant difference in the decay constants between the early and late cycles for naive CD4 cells $(-1.33$ vs. $-2.70 ; P=0.039)$, but not for any of the other subsets. Patients 1 and 2 similarly showed a very slow decay in the naive subpopulation (Figure 5), with decay constants of -2.72 and -3.52 , respectively.

\section{Discussion}

Using 2 independent in vivo labeling techniques, these studies have identified 2 mechanisms that contribute to the CD4 count increases seen in HIV-infected patients receiving intermittent IL-2 therapy. First, during IL-2 administration there is a dramatic increase in proliferation of both CD4 and CD8 cells, with a peak proliferation of CD4 cells that is significantly greater than that of CD8 cells. Second, the CD4 cells that proliferate during IL-2 administration have a profoundly prolonged survival. While the increased proliferation is probably necessary for the IL-2-induced CD4 count increases, it is not sufficient, since increased proliferation is also seen in nonresponding patients. Thus, the most critical effect in determining long-term CD4 cell increases in patients receiving intermittent IL-2 appears to be the increase in cell survival. The effects on survival were variable but could be quite remarkable, with CD4 half-lives of greater than 3 years for 2 patients. In support of our findings is a long-term decrease in Ki67 positivity in CD4 cells following IL-2 therapy (14). It is noteworthy that multiple IL-2 cycles appear to be necessary for these effects on survival to be seen. The mechanism for this time-dependent effect is uncertain but may be related to an incremental increase in longevity with each subsequent round of IL-2-induced proliferation. We are currently exploring the biologic mechanisms leading to an increase in survival of CD 4 cells. While immediate upregulation of $\mathrm{Bcl}-2$ expression has been reported in some patients receiving IL-2 (15), this may not explain the long-term effects that are seen.

IL-2 leads to a preferential increase in phenotypically naive CD4 cells, which likely results from an increase in peripheral expansion rather than an increase in thymic output (4-7). In 2 patients who received IL-2, high BrdU labeling of CD4 cells in lymph nodes (4\% and 19\%) was seen within 12 hours of BrdU administration. These data provide strong evidence in support of the hypothesis that peripheral expansion is the source of those cells. Consistent with this conclusion are the observations that thymic scans do not show an increase in size following IL-2, and that levels of $\mathrm{T}$ cell receptor excision circles in naive CD4 cells decrease in patients receiving $\mathrm{IL}-2(7,8)$.

The source of the IL-2-expanded cells thus appears to be preexisting CD4 cells. Based on these studies we cannot determine whether IL-2 has induced phenotypic changes in the expanded cells or has led to an expansion of select subsets without altering their phenotype. Work is underway to distinguish between these possibilities. While there is a preferential increase in naive cells, the increase in survival of CD4 cells is not exclusively a result of this preferential expansion of naive cells relative to memory cells, given the results noted in examination of purified subsets: among CD4 but not CD8 cells there was a significantly slower decay of deuterium-labeled naive cells with later IL-2 cycles compared with early cycles. While we cannot exclude the possibility that a subset of naive cells with a longer survival has been preferentially expanded, these data support the concept that IL-2 is directly increasing the survival of naive cells.

Although IL-2 leads to an expansion of naive CD4 cells in preference to memory CD4 cells, both populations in fact increase (4). When the kinetics of memory subpopulations were examined based on staining with CD27, CD45RA, and BrdU, the central memory 
pool $\left(\mathrm{CD} 27^{+} \mathrm{CD} 45 \mathrm{RO}^{+}\right)$had a prolonged survival compared with effector memory pools. These data suggest that, in addition to the effects on naive CD 4 cells, IL-2 differentially affects subpopulations of CD4 memory cells, leading to a preferential expansion of the central memory relative to the effector pool. Such a preferential expansion was demonstrated in IL-2 recipients participating in a randomized trial. While a significant change in decay constants for central memory cells was not seen with the deuterium labeling, this may be a result of the small number of patients $(n=3)$ in whom the decay of naive and memory cells was examined. Since the central memory cells appear to be primarily responsible for surveillance and reinitiation of immune responses against pathogens previously controlled by the host $(12,16)$, and since the majority of opportunistic infections seen in HIV-infected patients are caused by pathogens to which the host has previously been exposed, expansion of this pool of lymphocytes should potentially facilitate future control of these opportunistic infections. Similarly, these findings may account for the improved response to vaccination with a recall antigen seen in a recent study (17). However, based on these data, patients receiving IL-2 would not be expected to have improved immune function against pathogens causing active disease.

These findings are consistent with a recent study that examined changes in CD4 and CD8

\section{Figure 4}

BrdU labeling kinetics in 4 patients receiving a BrdU infusion immediately after the last IL-2 dose. (A) Experimental data for CD4 cells, represented by blue squares, and for CD8 cells, represented by red triangles. For patient 3 (top panels), data following labeling before any IL-2 was received are shown by green squares (CD4) and black triangles (CD8). The solid lines represent the fitting by the model equations. (B) The probability density function of the normal distribution of $\log d$ multiplied by the total source of labeled cells $(S)$ for the same patients. The last 2 patients were long-term responders (patients 1 and 19 from Figure 1). Mean log decay $m_{d}$ values for these data are (CD4/CD8): pt. 3, 0.10/-0.07 (for labeling with no IL-2), 0.14/0.88 (cycle 1); pt. $8,1.38 / 0.85$; pt. $1,-1.34 / 0.11$; pt. 19, $-1.28 / 0.35$. Consistent with the deuterium-labeling studies, the 2 long-term responders had a smaller $m_{d}$ for labeled CD4 but not CD8 cells, indicating longer survival of the proliferating cells. (C) BrdU labeling kinetics in naive (CD27+CD45RO-), central memory $\left(\mathrm{CD} 27^{+} \mathrm{CD} 45 \mathrm{RO}^{+}\right)$, and effector memory $\left(\mathrm{CD} 27^{-}\right.$ $\mathrm{CD}_{45 \mathrm{RO}^{+}}$and $\mathrm{CD}_{27}{ }^{-\mathrm{CD}} 45 \mathrm{RO}^{-}$) CD4 (top) and CD8 (bottom) subpopulations for patient 19. Presentation of data is as in A and B. For both CD4 and CD8 cells, $m_{d}$ is substantially smaller (indicating a slower decay) for the $2 \mathrm{CD} 27^{+}$populations. Mean log decay $m_{d}$ values for these data are (CD45RO-/CD45RO+): CD4/CD27+, -1.58/-1.10; CD8/CD27+, -1.02/-1.32; CD4/CD27-, 0.69/2.32; CD8/CD27-, 0.07/1.92.
A

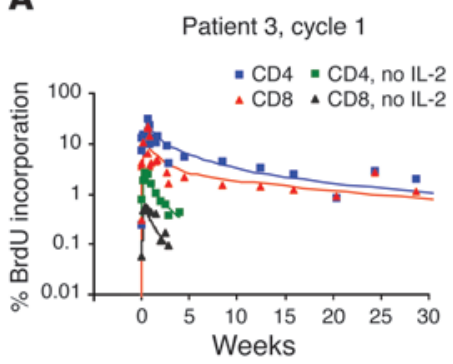

Patient 8 , cycle 3

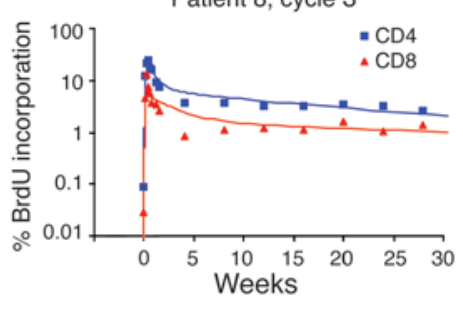

Patient 1 , cycle 8

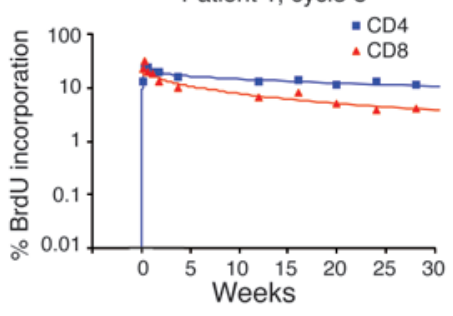

Patient 19 , cycle 12

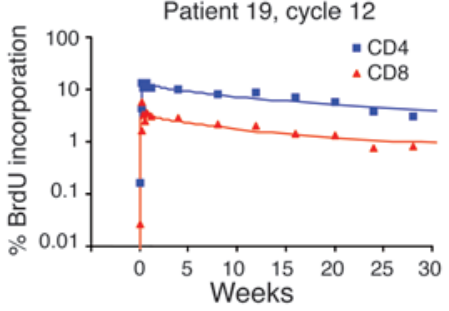

C
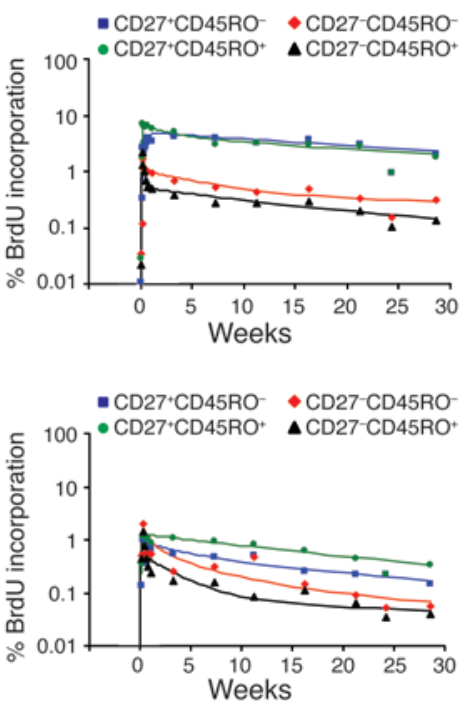

B

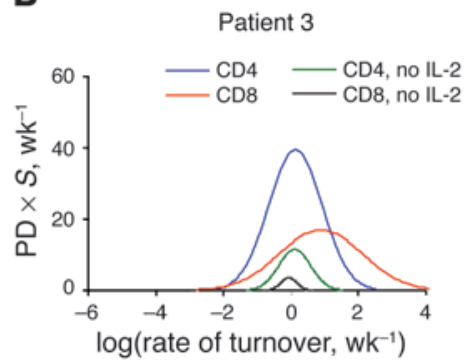

Patient 8

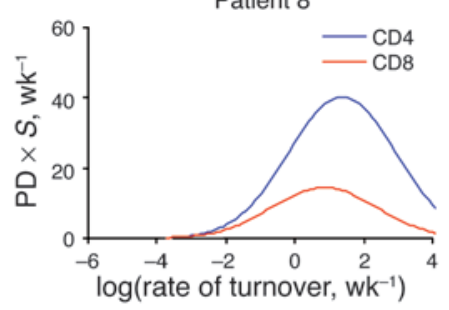

Patient 1

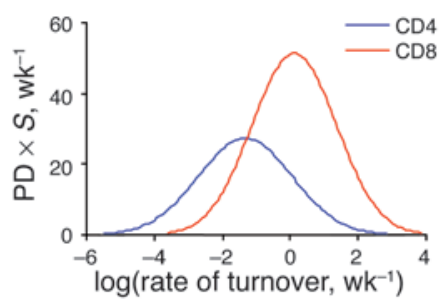

Patient 19

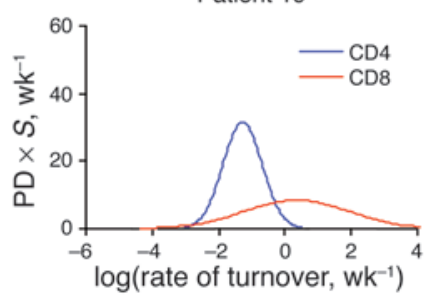

Patient 19
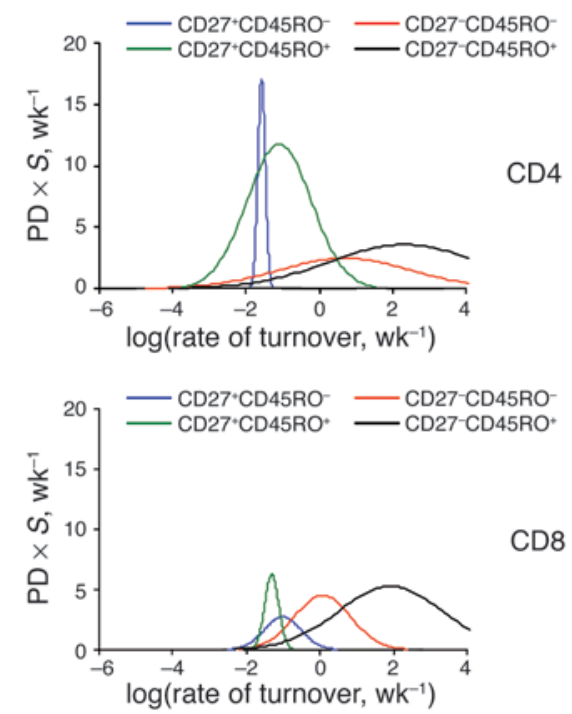
Table 3

Changes in naive and memory subsets of CD4 and CD8 cells in patients participating in a randomized trial of IL-2

\begin{tabular}{|c|c|c|c|c|c|c|c|c|c|c|}
\hline \multirow[b]{2}{*}{ Cohort } & \multicolumn{5}{|c|}{ CD4 (mean cells/ $\mu \mathrm{l}$ ) } & \multicolumn{5}{|c|}{ CD8 (mean cells/ul) } \\
\hline & Total & $\begin{array}{l}\text { Ro-/27+ } \\
\text { (naive) }\end{array}$ & $\begin{array}{c}\text { R0+/27+ } \\
\text { (central } \\
\text { memory) }\end{array}$ & $\begin{array}{l}\text { R0+/27- } \\
\text { (effector } \\
\text { memory) }\end{array}$ & $\begin{array}{l}\text { RO-/27- } \\
\text { (effector } \\
\text { memory) }\end{array}$ & Total & $\begin{array}{c}\text { Ro-/27+ } \\
\text { (naive) }\end{array}$ & $\begin{array}{l}\mathrm{RO}^{+} / 27^{+} \\
\text {(central } \\
\text { memory) }\end{array}$ & $\begin{array}{l}\mathrm{RO}+/ 27^{-} \\
\text {(effector } \\
\text { memory) }\end{array}$ & $\begin{array}{l}\text { Ro-/27- } \\
\text { (effector } \\
\text { memory) }\end{array}$ \\
\hline $\mathrm{IL}-2(n=11)$ & & & & & & & & & & \\
\hline Mo. 0 & 564 & 172 & 249 & 119 & 16 & 1,118 & 180 & 319 & 231 & 168 \\
\hline Mo. 6 & 911 & 301 & 427 & 157 & 18 & 1,191 & 186 & 379 & 202 & 176 \\
\hline $\begin{array}{l}\text { Mo. } 12 \\
\text { Control }(n=10)\end{array}$ & 828 & 261 & 394 & 142 & 21 & 1,122 & 174 & 360 & 179 & 167 \\
\hline Mo. 0 & 549 & 144 & 238 & 149 & 17 & 940 & 173 & 202 & 160 & 237 \\
\hline Mo. 6 & 567 & 165 & 268 & 112 & 18 & 867 & 195 & 216 & 118 & 204 \\
\hline $\begin{array}{l}\text { Mo. } 12 \\
P \text { value }^{\mathrm{A}}\end{array}$ & 623 & 182 & 278 & 137 & 19 & 956 & 198 & 231 & 142 & 224 \\
\hline Mo. 6 - Mo. $0^{\mathrm{B}}$ & & 0.020 & $<0.001$ & 0.092 & 0.796 & & 0.514 & 0.302 & 0.811 & 0.334 \\
\hline Mo. $12-$ Mo. $0^{B}$ & & 0.041 & 0.006 & 0.263 & 0.659 & & 0.194 & 0.770 & 0.487 & 0.719 \\
\hline
\end{tabular}

AComparison of the mean values for the 2 groups by Student's $t$ test. ${ }^{B}$ Represents the difference between the month 6 or the month 12 value and the baseline (month 0) value. RO, CD45RO; 27, CD27.

cell number and function in mice infected with lymphocytic choriomeningitis virus (LCMV). Administration of a single 7-day course of IL-2 at doses similar, on a weight basis, to those used in the current studies demonstrated no beneficial effects during the effector phase of LCMV infection, but beneficial effects were seen during the $\mathrm{T}$ cell contraction phase and stable memory phase. Furthermore, preferential survival of CD4 relative to CD8 cells was seen, and decreased apoptosis was seen compared with that in controls (18).

Our findings are also consistent with the clinical observations that IL-2's effects on disease progression are only apparent in long-term follow-up (19). The 2 phase III studies currently under way are designed to test this hypothesis and thus to determine the clinical efficacy of IL-2 $(13,20)$.

\section{Methods}

Patients. HIV-infected patients with no major clinical or laboratory abnormalities who were receiving intermittent IL-2 as a part of multiple ongoing studies to examine the potential role of IL-2 in the management of HIV infection were eligible for the study. Patients who were pregnant or breastfeeding, or (for BrdU) receiving 5-fluorouracil, were excluded from participation. All patients received approved antiretroviral drugs during IL-2 therapy. The specific regimen was determined by the patient and referring physician with input from the study team. Controls included HIV-infected patients who had never received IL-2 as well as healthy volunteers without $\mathrm{HIV}$ infection. ${ }^{2} \mathrm{H}$-glucose (Sigma-Aldrich or Cambridge Isotope Laboratories Inc.) was administered by continuous i.v. infusion over 5 days at a dose of $60 \mathrm{~g}$ per day. For patients receiving IL-2, the infusion began on the third day of IL-2 therapy and continued for 2 days after completion of the IL-2 cycle. Subjects underwent a 1- to 2-pass lymphapheresis to obtain cells for subsequent purification. BrdU was administered at a dose of $200 \mathrm{mg} / \mathrm{m}^{2}$ given i.v. by a 30-minute infusion, approximately 2 hours after the last IL-2 dose. All protocols were approved by the Institutional Review Board of the National Institute of Allergy and Infectious Diseases, and all patients provided written informed consent.

Laboratory studies. Determination of lymphocyte subsets and surface markers was performed as previously described $(21,22)$. In vivo labeling with BrdU and flow cytometric analysis of proliferating cells were per- formed as previously reported (11). In individual experiments, antibodies against either CD45RA or CD45RO were used to define naive and memory cells; for consistency, we report the results as $\mathrm{CD}_{4} 5 \mathrm{RO}^{+}$(approximately equivalent to $\mathrm{CD}^{2} \mathrm{RA}^{-}$) or $\mathrm{CD}^{2} 5 \mathrm{RO}^{-}$(approximately equivalent to $\mathrm{CD} 4 \mathrm{RA}^{+}$). Plasma HIV levels were measured using the VERSANT HIV-1 RNA 3.0 Assay (Bayer HealthCare AG).

To determine deuterium incorporation, peripheral blood $\mathrm{CD} 4^{+} \mathrm{T}$ cells and $\mathrm{CD}^{+} \mathrm{T}$ cells were isolated by fluorescence-activated cell sorting, using an EPICS ALTRA flow cytometer (Beckman Coulter Inc.) or BD FACSVantage SE FACSDiVa (BD Biosciences), to greater than $99.0 \%$ purity. For analysis of naive and memory $\mathrm{CD} 4^{+} \mathrm{T}$ cells, PBMCs were enriched for $\mathrm{CD} 4^{+} \mathrm{T}$ cells by removal of monocytes and CD8 $8^{+}$lymphocytes using anti-CD14- and anti-CD8-coated magnetic beads (Dynal Biotech). The $\mathrm{CD}^{+}$lymphocytes removed in this step were used later to sort for the $\mathrm{CD} 8^{+}$memory and naive subsets. The remaining lymphocytes were then stained according to the manufacturer's instructions with the mAbs CD27-FITC (BD Biosciences), CD45RO-PE (BD Biosciences), and CD4-PC5 (Beckman Coulter Inc.). Sorting was performed using an amorphous forward light scatter and $90^{\circ}$ light scatter gate and rectilinear gates on $\mathrm{CD} 27^{+} \mathrm{CD} 45 \mathrm{RO}^{-} \mathrm{CD} 4^{+}$(naive), $\mathrm{CD} 27^{+} \mathrm{CD} 45 \mathrm{RO}^{+} \mathrm{CD} 4^{+}$(central memory), and $\mathrm{CD} 27^{-} \mathrm{CD} 45 \mathrm{RO}^{+} \mathrm{CD} 4^{+}$(effector memory) cells; subset purity was determined by flow cytometry to be greater than $98.0 \%$. For CD 4 cells, there were too few $\mathrm{CD} 27^{-} \mathrm{CD} 45 \mathrm{RO}^{-}$cells for analysis. For isolation of naive and memory $\mathrm{CD}^{+} \mathrm{T}$ cells, the $\mathrm{CD} 8^{+}$lymphocytes removed by bead separation were treated with DETACHaBEAD (Dynal Biotech) to remove the attached magnetic beads. The $\mathrm{CD}^{+}$lymphocytes were then stained with the mAbs CD27-FITC, CD45RO-PE, and CD8-PC5 (Beckman Coulter Inc.). Sorting was performed as above with rectilinear gates on $\mathrm{CD}_{27} 7^{+} \mathrm{CD} 45 \mathrm{RO}^{-} \mathrm{CD} 8^{+}$(naive), $\mathrm{CD} 27^{+} \mathrm{CD} 45 \mathrm{RO}^{+} \mathrm{CD}^{+}$(central memory), CD27-CD45RO ${ }^{+} \mathrm{CD}^{+}$(effector memory), and $\mathrm{CD} 27^{-} \mathrm{CD} 45 \mathrm{RO}^{-} \mathrm{CD}^{+}$(effector memory) cells; subset purity was determined to be greater than $98.0 \%$.

Quantitation of ${ }^{2} \mathrm{H}$-glucose enrichment in serum and ${ }^{2} \mathrm{H}$-deoxyadenosine enrichment in genomic DNA. Glucose was extracted from serum with methanol and converted to the aldonitrile penta-acetate derivatives of glucose (217 massto-charge ratio $[\mathrm{m} / \mathrm{z}])$ and ${ }^{2} \mathrm{H}$-glucose $(219 \mathrm{~m} / z)$ for gas chromatography/ mass spectrometry spectral analysis using an HP 5890 gas chromatograph (Hewlett-Packard Co.) interfaced to an HP 5971 mass selective detector (Hewlett-Packard Co.) (23). Sample enrichments were calculated by comparison with standard curves prepared from ${ }^{2} \mathrm{H}$-glucose. 
Genomic DNA was hydrolyzed to mono-deoxyribonucleosides with deoxyribonuclease I, phosphodiesterase I, and bacterial alkaline phosphatase, desalted using Oasis HLB 96-well extraction plate (Waters Corp.), and either converted to the permethylated derivatives of deoxyadenosine $(292 \mathrm{~m} / z)$ and ${ }^{2} \mathrm{H}$-deoxyadenosine $(294 \mathrm{~m} / \mathrm{z})$ for gas chromatography/mass spectrometry analysis or analyzed directly by liquid chromatography/mass spectrometry as described in ref. 24. Sample enrichments were calculated by comparison with standard curves prepared from ${ }^{2} \mathrm{H}$-deoxyadenosine.

To determine the amount of new DNA that was synthesized, the experimentally determined percentage of ${ }^{2} \mathrm{H}$-deoxyadenosine enrichment was corrected as previously described (9) to account for the following factors: (a) the maximum labeling of freshly obtained lymphocytes cultured in vitro in the presence of $100 \%{ }^{2} \mathrm{H}$-glucose, which was approximately $60 \%$; and (b) the level of enrichment of ${ }^{2} \mathrm{H}$-glucose in the serum, typically about $20 \%$ to $30 \%$.

Modeling and statistical analysis. Initially, decay constants were estimated by linear regression of log-transformed data for the first 120 days after the labeling; for the 2 longterm responders, decay estimates were based on all available data. Because linear regression provided a relatively poor fit to the actual data, we developed a semiempirical model to better describe the kinetics and estimate decay constants. We have previously developed a model of the dynamics of $\mathrm{T}$ cells in blood labeled with BrdU that was fitted to experimental data for HIV-infected patients with relatively stable levels of plasma HIV concentrations (11). According to this model, the fraction of labeled cells $L$ in each cell subpopulation with turnover rate constant $d\left(\mathrm{wk}^{-1}\right)$ and source of labeled cells $s\left(\mathrm{wk}^{-1}\right)$ can be calculated as $d L / d t=s U-d L$, where $U$ is a unit function dependent on the time $T$ required to reach the maximum value of $L$ :

\section{Equation 1}

$$
U(t)= \begin{cases}1, & t \leq T \\ 0, & t>T\end{cases}
$$

We have previously found that at least 2 or more (likely 3 or more) dynamically distinct cell subpopulations contribute to the $\mathrm{T}$ cell dynamics (11). The individual variation of the rate constants among patients was relatively large, thus further suggesting the existence of many cell subpopulations. To account for the diversity of cell dynamic constants, we have extended our previous analysis, assuming that the rate of turnover $d$ is continuously distributed with a probability density function $F(d, \alpha)$, where $\alpha$ is a vector of parameters. Thus, the source $s_{i}$ of cells with turnover rate constants in the interval $\left[D_{i-1}, D_{i}\right]$ can be calculated as:

\section{Equation 2}

$$
s_{i}=S \int_{D_{i-1}}^{D_{i}} F(x, \alpha) d x
$$

where $S$ is the total source of all labeled cells. The total population of labeled cells can be subdivided into $I$ subpopulations with sources $s_{i}(i=1, \ldots, I)$ and rates of turnover $d_{i}(i=1, \ldots, I)$ where $d_{i}=\left(D_{i-1}+D_{i}\right) / 2$. Then the dynamics of the $i$ th labeled cell subpopulation $L_{i}$ with parameters
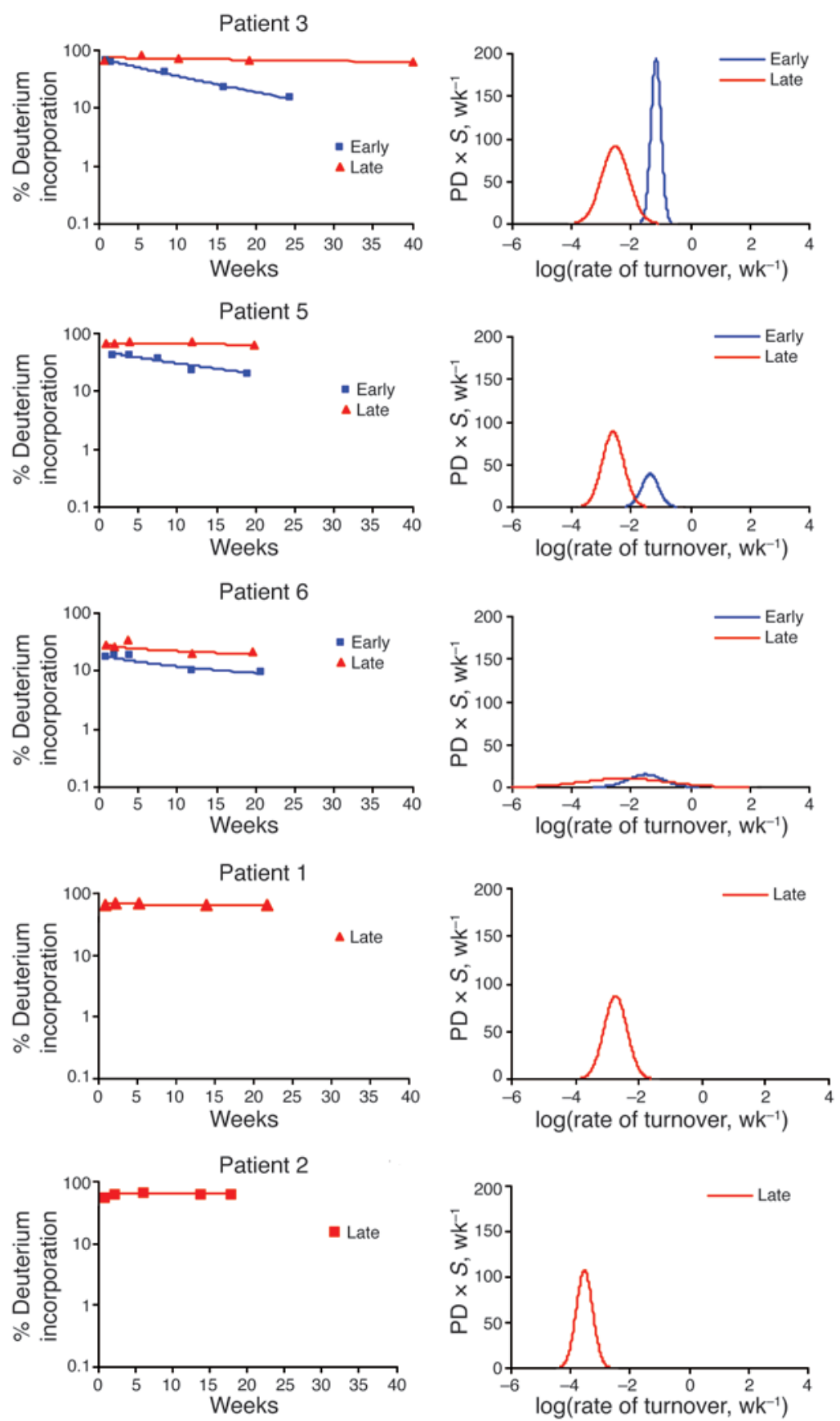

\section{Figure 5}

Deuterium labeling kinetics in naive $\left(\mathrm{CD} 27^{+} \mathrm{CD} 45 \mathrm{RO}^{-}\right)$cells in patients receiving IL-2. The left panels show the measured data (symbols) and the fitting by the model equations (solid lines) for patients 3,5 , and 6 following an early cycle (blue) and a later cycle (red), and for patients 1 and 2 following the single late IL-2 cycle; the right panels show the probability density function of the normal distribution of log $d$ multiplied by the total source of labeled cells $(S)$. Mean log decay $m_{d}$ values for these data are (early/late): $-1.16 /-2.52,-1.35 /-2.61$, and $-1.49 /-2.14$ for patients 3,5 , and 6 , respectively ( $P=0.039$ for early vs. late, Student's $t$ test), and -2.72 and -3.52 for patients 1 and 2, respectively. No significant change was seen in the mean log decay $m_{d}$ for the other CD4 subsets or for any of the CD8 subsets for patients 3,5 , and 6 . Average values for mean log decay $m_{d}$ for these subsets were as follows (early/late): CD4 central memory $\left(C D 27^{+} \mathrm{CD} 45 \mathrm{RO}^{+}\right),-0.54 /-0.70$; CD4 effector memory (CD27CD45RO $\left.{ }^{+}\right),-0.59 /-0.74$; CD8 naive (CD27+CD45RO-), $-1.00 /-1.90$; CD8 central memory $\left(\mathrm{CD} 27^{+} \mathrm{CD} 45 \mathrm{RO}^{+}\right),-0.82 /-1.26$; CD8 effector memory (CD27-CD45RO ${ }^{+}$), $-0.19 /-0.36$; CD8 effector memory (CD27-CD45RO-), $-1.02 /-1.13$. 
$s_{i}$ and $d_{i}$ can be calculated using the equations shown above but applying them to each subpopulation. The total fraction of labeled cells $L$ is equal to the sum of all $L_{i}: L=L_{1}+\ldots+L_{I}$.

We tested several standard distributions and found that the best fit for all patients was given by the log-normal distribution of the turnover rates with mean $m_{d}$ and standard deviation $\sigma_{d}$. The interval of mean log decay rate constants $\left[D_{0}, D_{I}\right]=\left[m_{d}-3 \sigma_{d}, m_{d}+3 \sigma_{d}\right]$ was used for calculations. The 3 parameters, $S, m_{d}$, and $\sigma_{d}$, were obtained by fitting of the experimental data for each patient to the solution of the differential equation for $L$ using this function. Numerical simulations demonstrated that $I=7$ accurately represents the continuous distribution; simulations for $I>7$ showed no significant improvements. (Use of the same approach, applied to a different problem, also suggested that $I \geq 7$ is sufficient for accurate representation of the distribution; ref. 25).

Since the administration of IL-2 disrupts the steady state, and shifts in cell number are likely the result of substantial trafficking as well as proliferation and apoptosis until the return to a steady state, our modeling focused on the percentage of labeled cells rather than the absolute number of labeled cells. Under the assumption that the IL-2-induced perturbations to steady state affect cells globally, the calculated decay kinetics would be reflective of the death rate of the labeled population of cells.

Significance levels were calculated using the 2-tailed Student's $t$ test, nonparametric rank sum test, or signed-rank test. Two-sided $P$ values of less than 0.05 were considered significant.

1. Kovacs, J.A., et al. 1996. Controlled trial of interleukin-2 infusions in patients infected with the human immunodeficiency virus. N. Engl. J. Med. 335:1350-1356.

2. Davey, R.T., Jr., et al. 2000. Immunologic and virologic effects of subcutaneous interleukin 2 in combination with antiretroviral therapy: a randomized controlled trial. JAMA. 284:183-189.

3. Levy, Y., et al. 1999. Comparison of subcutaneous and intravenous interleukin-2 in asymptomatic HIV-1 infection: a randomised controlled trial. ANRS 048 study group. Lancet. 353:1923-1929.

4. Kovacs, J.A., et al. 2001. Interleukin-2 induced immune effects in human immunodeficiency virusinfected patients receiving intermittent interleukin2 immunotherapy. Eur. J. Immunol. 31:1351-1360.

5. Davey, R.T., Jr., et al. 1999. A randomized trial of highversus low-dose subcutaneous interleukin-2 outpatient therapy for early human immunodeficiency virus type 1 infection. J. Infect. Dis. 179:849-858.

6. De Paoli, P., et al. 2001. Changes in thymic function in HIV-positive patients treated with highly active antiretroviral therapy and interleukin-2. Clin. Exp. Immunol. 125:440-446.

7. Natarajan, V., et al. 2002. Increased peripheral expansion of naive CD4+ $\mathrm{T}$ cells in vivo after IL-2 treatment of patients with HIV infection. Proc. Natl. Acad. Sci. U. S. A. 99:10712-10717.

8. Lu, A.C., et al. 2003. Increases in CD4+ T lymphocytes occur without increases in thymic size in HIVinfected subjects receiving IL-2 therapy. J. Acquir. Immune Defic. Syndr. 34:299-303.

9. Hellerstein, M., et al. 1999. Directly measured

\section{Acknowledgments}

We would like to thank the patients for their willingness to participate in these studies, Anthony Fauci for his helpful discussions, and the outpatient and inpatient National Institute of Allergy and Infectious Diseases and Clinical Center staff. IL-2 was provided by Chiron Corp. This project has been funded with federal funds from the Department of Health and Human Services under contract number NO1-CO-12400. The content of this publication does not necessarily reflect the views or policies of the Department of Health and Human Services, nor does mention of trade names, commercial products, or organization imply endorsement by the US government.

Received for publication August 27, 2004, and accepted in revised form May 24, 2005.

Address correspondence to: Joseph A. Kovacs, Building 10, Room 7D43, Mail Stop Code 1662, Bethesda, Maryland 208921662, USA. Phone: (301) 496-9907; Fax: (301) 402-1213; E-mail: jkovacs@niaid.nih.gov.

This work was presented in part at the 9th Conference on Retroviruses and Opportunistic Infections in Seattle, Washington, USA, on February 24-28, 2002 (Abstract no. 103). kinetics of circulating $\mathrm{T}$ lymphocytes in normal and HIV-1-infected humans. Nat. Med. 5:83-89.

10. Mohri, H., et al. 2001. Increased turnover of T lymphocytes in HIV-1 infection and its reduction by antiretroviral therapy. J. Exp. Med. 194:1277-1287.

11. Kovacs, J.A., et al. 2001. Identification of dynamically distinct subpopulations of T lymphocytes that are differentially affected by HIV. J. Exp. Med. 194:1731-1741.

12. Sallusto, F., Lenig, D., Forster, R., Lipp, M., and Lanzavecchia, A. 1999. Two subsets of memory T lymphocytes with distinct homing potentials and effector functions. Nature. 401:708-712.

13. Emery, S., et al. 2002. The evaluation of subcutaneous proleukin (interleukin-2) in a randomized international trial: rationale, design, and methods of ESPRIT. Control. Clin. Trials. 23:198-220.

14. Sereti, I., et al. 2004. IL-2-induced CD4+ T-cell expansion in HIV-infected patients is associated with long-term decreases in T-cell proliferation. Blood. 104:775-780.

15. David, D., et al. 2002. Involvement of $\mathrm{Bcl}-2$ and IL-2R in HIV-positive patients whose CD4 cell counts fail to increase rapidly with highly active antiretroviral therapy. AIDS. 16:1093-1101.

16. Hengel, R.L., et al. 2003. Cutting edge: L-selectin (CD62L) expression distinguishes small resting memory CD4+ $\mathrm{T}$ cells that preferentially respond to recall antigen. J. Immunol. 170:28-32.

17. Levy, Y., et al. 2003. Effects of interleukin-2 therapy combined with highly active antiretroviral therapy on immune restoration in HIV-1 infection: a randomized controlled trial. AIDS. 17:343-351.
18. Blattman, J.N., et al. 2003. Therapeutic use of IL-2 to enhance antiviral T-cell responses in vivo. Nat. Med. 9:540-547.

19. Emery, S., et al. 2000. Pooled analysis of 3 randomized, controlled trials of interleukin-2 therapy in adult human immunodeficiency virus type 1 disease. J. Infect. Dis. 182:428-434.

20. Pett, S.L, and Emery, S. 2001. Immunomodulators as adjunctive therapy for HIV-1 infection. J. Clin. Virol. 22:289-295.

21. Connors, M., et al. 1997. HIV infection induces changes in CD4+ T-cell phenotype and depletions within the CD4+ T-cell repertoire that are not immediately restored by antiviral or immune-based therapies. Nat. Med. 3:533-540.

22. [Anonymous]. 1994. 1994 revised guidelines for the performance of CD4+ T-cell determinations in persons with human immunodeficiency virus (HIV) infections. Centers for Disease Control and Prevention. MMWR Recomm. Rep. 43:1-21.

23. Magni, F., et al. 1992. Determination of plasma [6,6-2 $\mathrm{H} 2]$ glucose enrichment by a simple and accurate gas chromatographic-mass spectrometric method. J. Chromatogr. 573:127-131.

24. Fox, S.D., et al. 2003. A comparison of microLC/ electrospray ionization-MS and GC/MS for the measurement of stable isotope enrichment from a $\left[{ }^{2} \mathrm{H}_{2}\right]$-glucose metabolic probe in T-cell genomic DNA. Anal. Chem. 75:6517-6522.

25. Sidorov, I.A., Hirsch, K.S., Harley, C.B., and Dimitrov, D.S. 2002. Cancer cell dynamics in presence of telomerase inhibitors: analysis of in vitro data. J. Theor. Biol. 219:225-233. 